\title{
Parental Dissolution and the Transmission of Relational Instability for Adult Children of Divorce
}

\author{
Ashley Foo ${ }^{1}$
}

\begin{abstract}
This paper explores the ways in which divorce has an effect on adult children of divorce and their perception towards intimate relationships. Current research around the topic suggests that individuals raised in divorced families tend to develop less positive attitudes towards marriage, and more positive attitudes towards divorce. This concept stems from the types of experiences gained through an individual's family-of-origin, this creates a clear indication surrounding the attitudes a child of divorce will carry through to their intimate relationships. I will discuss a common source of tension around 'feeling caught' between parents and the impact it has on communication and topic avoidance. The topic centers around the concept of relational uncertainty and its association to relational turbulence and reactivity. The portrayal of parental relationships influences the transmission of marital instability.
\end{abstract}

\footnotetext{
${ }^{1}$ MacEwan University
} 


\section{Introduction}

Divorce, also known as a dissolution of a marriage, is the process of legally terminating a marital union by a court or other competent body. In society today, divorce has become a normalized concept happening more frequently than one may anticipate or expect. Many people evade the topic of divorce itself within conversation due to the rippling effect this separation has on every party involved. A substantial amount of research has been published in regards to the impact divorce has on young children and the parent-child relationship. This attention towards children of divorce is especially high due to the crucial developmental period they exhibit. A dissolution of marriage directly affects children living in the household through the environmental and relational changes that are consequential to the separation. This extreme focus on younger children and their handling of divorce often disregards the impact this split may have on older children.

Adult children of divorce, also known as ACOD, are categorized from the age of eighteen and older. When dealing with the tumultuous situation of divorce, parents often overlook the fact that their children are still their children regardless of age and thus, consider them more like a friend in which they can vent to (Mikucki-Enyart, Petitte \& Wilder, 2018, p. 484). Parental conflict and negative disclosures towards one another can spill over onto children, particularly when children become privy to such interactions (Afifi \& Schrodt, 2003, p. 143). There are indications that children from divorced households often avoid talking about the state of their family in front of their parents in order to prevent 'feeling caught' (Afifi \& Schrodt, 2003, p. 143). This state of tension is not exclusive to adolescents as ACOD struggle with feeling caught in the middle and having to renegotiate family rituals. When a child feels caught within the relationship that can lead to the formation of alliances with specific parents and can be directly associated with problematic interpersonal communication patterns (Afifi \& Schrodt, 2003, p. 145). Individuals raised in divorced families tend to develop less positive attitudes towards marriage, and more positive attitudes towards divorce. These negative attitudes towards marital unions leads to decreased commitment in romantic relationships, lowering the quality of the relationship and therefore compromising the individuals emotional and relational stability (Cui \& Fincham, 2010, p. 332).

Adult children of divorce are an overlooked, yet growing population that are erroneously thought to be unaffected by their parents' divorce due to age, independence, and maturity (Mikucki-Enyart et al., 2018, p. 483). Divorce can have a substantial impact on adult children as it takes place during a significant period in which individuals develop the capacity to form and maintain relationships. ACOD experience a myriad of uncertainties following a separation specifically towards the familial dynamic, individual identity, relational uncertainty, and the future of intimate relationships as a whole. The dissolution of the family-of-origin creates patterns of uncertainties and inference in adult children of divorce as they balance other normative developmental stressors, such as their own personal journey into marriage and parenthood (Mikucki-Enyart et al., 2018, p. 474). Within this paper, I hypothesize that the experiences adult children of divorce have in their families-of-origin have a significant effect upon young people's attitudes towards future relationships. This interpretation is linked with the development of relational uncertainty from the dissolution of marriage mediating the association between com- 
munication and relational turbulence. Furthermore, I propose that divorce influences the transmission of marital instability through the development of interpersonal communicative behaviours in direct relation to topic avoidance and relational turbulence. In addition, I will be acknowledging potential recommendations drawn from the studies mentioned regarding ways in which parents can mediate these uncertainties early on.

\section{Literature Review}

Divorce can directly affect adult children's perceptions on intimate relationships, resulting in relational uncertainty. Relational Uncertainty can be understood as the degree of confidence the relational partners have surrounding the involvement within the interpersonal relationship. This concept centres around questions regarding one's own self uncertainty or partner uncertainty when considering the commitment, thus creating relationship uncertainty as well (Mikucki-Enyart et al., 2018, p. 470). Relational uncertainty retains narrowly to an individual's doubts surrounding how people manage, negotiate, and experience close relationships (Carpenter-Theune \& Knobloch, 2004, p. 178). This concept originates from three interrelated, yet distinct sources: the self, the partner, and the relationship (Carpenter-Theune \& Knobloch, 2004, p. 178). Self uncertainty refers to the questions people have surrounding their personal involvement within the relationship. Partner uncertainty involves the ambiguity people experience about their partner within this association. Relationship uncertainty concerns the doubts people have about the nature of the relationship apart from the self or partner issues (Carpenter-Theune \& Knobloch, 2004, p. 178). Mikucki-Enyart et al. (2018) recognize the effects divorce has on adult children and the acquisition of relational uncertainty. They conduct a study utilizing uncertainty management theory to understand how ACOD manage these relational uncertainties following parental divorce and the implications it may have towards communication outcomes as well as behavioural attempts to manage this uncertainty. The Uncertainty Management Theory (UMT) rejects the narrative that uncertainty is a bad thing and needs to be reduced, rather it focuses on the appraisal individuals give uncertainty, whether it be positive or negative, and how it may prove beneficial and not detrimental (Mikucki-Enyart et al., 2018, p. 471).

In the study by Mikucki-Enyart et al. (2018), they recruited participants whose parents divorced when they were eighteen years or older living independently at the time of the divorce (p. 474). The results demonstrate different strategies ACOD use in order to obtain knowledge around the dissolution in an attempt to reduce relational uncertainty. The evaluation an individual gives this uncertainty shapes the way in which they acquire information, ultimately making it a goal-oriented behaviour (Mikucki-Enyart et al., 2018, p. 471). These strategies are conceptualized into two categories: deliberate and incidental information acquisition. Deliberate information seeking is the purposeful and intentional pursuit of reducing uncertainty and facilitating coping. It encourages direct communication and works to reduce ambiguity, promoting sustained intimacy and affection amongst parents and adult children (Mikucki-Enyart et al., 2018, p. 481). This demonstrates how uncertainty and emotional appraisal work simultaneously to shape information acquisition strategies (Mikucki-Enyart et al., 2018, p. 476). Although information-seeking may be beneficial, it can also pose as a constraint if individuals doubt their ability to effectively seek 
information. The inability to satisfy this expectation prevents ACOD to achieve their aim of reducing uncertainty and further, their ability to cope (Mikucki-Enyart et al., 2018, p. 477). Incidental information acquisition is the result of unprovoked and inappropriate parental disclosure. This in itself presents as a constraint as some adult children purposefully avoid acquiring information in fear of revelation of unwanted information as it creates potential to maintain uncertainty rather than reduce it. Incidental information acquisition can promote 'feeling caught' between the parent's divorce, a concept also known as parentification (Mikucki-Enyart et al., 2018, p. 484). The results of the study done by Mikucki-Enyart et al. (2018) highlight the importance of examining the experiences of adult children of divorce (p. 483). They first acknowledge how ACOD manage additional normative and developmental life stressors that complexify uncertainty and the ways in which they manage it. They go on to describe the concept of the 'sandwich generation' as ACOD are expected to support themselves and their parents, finding a balance between uncertainty and communication. Lastly, they address communicative differences experienced by adolescents compared to adult children who are no longer living at home and experiencing parentification (Mikucki-Enyart et al., 2018, p. 484). Unlike adolescents, many adults were able to vocalize their discomfort when faced with incidental information acquisition and able to mitigate the conversation.

\section{Feeling Caught and Psychological Well-being}

When compared to young adults, adolescents may lack cognitive or communicative skills to directly confront their parents when experiencing the tension of 'feeling caught' between them. Even if the adolescent is comfortable talking to their parents, they may not hold the cognitive complexity or communicative competence to effectively address the issue (Afifi \& Schrodt, 2003, p. 147). Thus, resulting in avoidant behaviour as they feel that to be the only appropriate response. In comparison to adult children of divorce, many have developed a greater ability to communicate with their parents' and anticipate their response (Afifi \& Schrodt, p. 147). In the study by Afifi and Schrodt (2003) they apply a model of feeling caught to children of divorced and non-divorced households to assess its fit across the two groups (p. 143). The model predicts that children of divorced families will report less closeness and satisfaction, greater feelings of being caught, less parental communication competence, and more parental demand compared to children of nondivorced families (Afifi \& Schrodt, 2003, p. 145). As Afifi and Schrodt (2003) state, "the general communication competence of the parents is likely to be predictive of children's feelings of being caught" (p. 149). If a child feels as though they cannot speak to their parents regarding the other without being put in the middle, they move to internalization or avoidance of the issues at hand. This may suggest that children become triangulated between their parents and are likely to be drawn into their conflicts and stress (Afifi \& Schrodt, 2003, p. 145).

The exposure to hostile parental interactions teaches children what may be an ineffective way of managing conflict that can directly impact their physical and mental health (Afifi \& Schrodt, 2003, p. 143). The study by Leustek and Theiss (2017) suggest that the communication

orientations of each parent in divorced families correspond directly with emerging adults' perceptions of feeling caught and relational turbulence (p. 170). When parents use their children 
in a triangular manner, it promotes feelings of being caught and increases conflict. This study aimed to identify how ACOD's psychological well-being is associated with family dynamics in a post-divorce context (Leustek \& Theiss, 2017, p. 170). The patterns of communication that the family exhibits is an indication of whether or not ACOD feels caught and the way in which they perceive relational turmoil. A number of psychological issues may emerge for adult children of divorce given the increased awareness during the divorce process, one particular mental health issue being depression (Leustek \& Theiss, 2017, p. 173). A main feature of late-life divorce in ACOD is feeling caught between parents, this characteristic is positively associated with depressive symptoms and negatively associated with resilience for emerging adult children (Leustek \& Theiss, 2017, p. 174). Although emerging adult children may have the maturity to participate in conversation regarding the dissolution of marriage, the results of Leustek and Theiss' (2017) study indicate the negative effects that inappropriate disclosure can have on their psychological well-being (p. 184).

\section{Social Learning Theory and the Transmission of Marital Instability}

Children internalize their parents' conflict and are likely to demonstrate this through their conversation with parents (Afifi \& Schrodt, 2003, p. 143). According to the social learning theory, children learn many behaviours through the observation of adult models (Amato \& Deboer, 2001, p. 1039). Parents in particular represent the most important source for which children learn as our families are our first socialization agents. They demonstrate the nature of intimate relationships as well as specific marital behaviours. Children gain a variety of interpersonal skills through the observation of these adult models, for these reasons, children whose parents divorce have fewer opportunities to observe and develop positive behaviours that facilitate long-term bonds with others than do other children (Amato \& Deboer, 2001, p. 1040).

Based on social learning theory, it is likely that parental divorce influences young adults' romantic relationships through shaping their attitudes towards marriage and divorce which overall reflects their commitment to the relationship (Cui \& Fincham, 2010, p. 331). Parental divorce can increase the likelihood that children develop interpersonal behaviours that undermine intimate relationships and increase the risk of marital instability in adulthood (Amato \& Deboer, 2001, p. 1040). This being due to communication problems demonstrated throughout the maritally distressed union. Thus, some young adults may shape their behaviour in their romantic relationships by observing marital interactions between their parents. The development of conflict behaviours and attitudes towards marriage and divorce will directly affect their own romantic relationships throughout their commitment (Cui \& Fincham, 2010, p. 331).

In the study by Knobloch and Soloman (2004), the article aims to identify relational uncertainty and interference from partners as relationship development processes that may account for increased relationship turbulence during the transitionary period from casual dating to serious involvement (p. 796). Relational turbulence inherently accompanies the redefinition of a relationship and can be credited as a by-product of emerging intimacy in romantic associations (Knobloch \& Solomon, 2004, p. 796). If an individual is predisposed to relational uncertainty, interference from a partner redefining the relationship may give rise to turbulence during the 
transitionary period. The analysis within this study concludes that relational uncertainty is an important mechanism underlying relational turbulence in which promotes reactivity, especially at moderate levels of intimacy, creating difficulties during the transition from casual to serious involvement (Knobloch \& Solomon, 2004, p. 811). Having this form of reactivity to relationship progression coincides with issues surrounding intimacy and relational uncertainty and therefore acts as a marker of progression within courtship. In the study by Carpenter-Theune and Knobloch (2004), they take a developmental perspective on relationships and the way in which individuals make sense of them at various points considering the changing variables of the relationship ( $\mathrm{p}$. 174). They recognize the tumultuous period elicited from the transition from casual dating to serious involvement and hypothesized that relational uncertainty is especially prominent during this period (Carpenter-Theune \& Knobloch 2004, p. 174).

\section{Communication and Message Quality}

Taking into consideration the social learning theory and the ways in which parental models shape interpersonal behaviours, the messages communicated can be directly associated to an individual's belief system. The study by Weigel (2007) aims to examine the influences of types of commitment-related messages gained from families of origin and to what degree do those messages affect their beliefs surrounding intimate relationships (p. 16). The results of this study indicate that people with divorced or unhappy parents were more likely to gain messages such as, relationships are not permanent, one must approach relationships with causes, and less likely to receive messages insisting relationships are happy and enduring (Weigel, 2007, p. 16). Participants indicated that they felt those messages had influenced their experiences in relationships concluding the importance the family of origin has on people's attitudes regarding romantic relationships (Weigel, 2007, p. 16). Through these experiences, people learn both direct and indirect lessons about what intimate relationships are supposed to look like. If a relationship has only been modelled through divorce, general opinions about commitment and love will be shaped around those messages. Weigel (2007) discusses an intergenerational approach to relationship outcomes to explain the association between early family experiences and later attitudes about romantic relationships (p. 17). These findings support the idea that experiences an individual gains from their family can directly influence the specific types of messages surrounding commitment and intimate relationships people recall and the beliefs they hold moving forward (Weigel, 2007, p. 28).

\section{Personal Reference}

My interest towards the topic of divorce and the ways it impacts adult children of divorce's perceptions of intimate relationships revolved around a personal experience of mine in which I was eager to explore.

I always thought marriage was inevitable and that was the framework I modelled my life after. You grow up, fall in love, get married, and start a family. It was not until three years ago 
when my parents divorced had I reconsidered this framework. Seeing first hand how messy a separation can be, despite how beautiful the duration of the relationship was, slandered the possibility of marriage for myself. Considering I was eighteen when my parents divorced, both my mother and father felt they could confide in me as I was the only one of my two other siblings still living at home. As mentioned previously by Afifi and Schrodt (2003) parental conflict is often internalized by the child, especially if the child becomes triangulated between their parents. Mediating my parents problematic communication patterns placed myself in a position of tension, feeling caught between the two with neither of them recognizing a problem. A position I found myself in as highlighted by Enyart et al. (2018) balancing the desire to seek and avoid information in order to reduce my uncertainty all while working to protect myself and my parents. My information seeking started as deliberate looking for causations and reasoning as to why the relationship was ending. This purposeful form of information acquisition soon turned into incidental as I was being told information I no longer seek. As mentioned by Enyart et al. (2018), these communicative differences have implications for managing uncertainty and creating boundaries. Afifi and Schrodt (2003) study makes the comparison between adolescents and young adults communication competence when negotiating boundaries for communication with parents (p. 483). Although most young adults obtain the necessarily skills to persuade their parents to comply with their request to modify conflict styles, in my case, I took the route of avoidance as it caused me the least anxiety (p. 149). In my situation, I felt as though I was in what Enyart et al. (2018) described as a 'sandwich generation' where I found challenges in balancing my uncertainty, communication with parents, along with my own personal stressors with individual identity. Overall, I agree with Weigel (2007) research examining how the types of commentary and communication you experience from your family-of-origin influences your attitudes towards marriage and intimate relationships. Throughout this situation, my dad would reitorate ideas that love is not real and nothing lasts, indicating a negative perception towards relationships as a whole. My mother would encourage myself to never settle and to not marry young as the complexification of relationships intensify once finances, children, and lifestyles are incorporated. Both ideas instilled beliefs in my mind that I still address constantly when entering new relationships.

\section{Ways in which Parents can Mediate the Hurt}

Divorce is not an easy concept and more often than not, it gets messy whether that be intentional or not. Children often reported feeling caught between parents, but their parents did not recognize this state of tension as a problem (Afifi \& Schrodt, 2003, p. 143). Considering the significant impact divorce and the family of origins experiences can have on ACOD, recommendations have been listed from the following articles in an attempt to mitigate. The study by Afifi and Schrodt (2003) indicate that the variations in which children respond to divorce could be mediated by their parents problematic interpersonal communication patterns and the degree in which the child becomes immersed in them (p. 145). The ways in which parents handle the marital dissolution can be a reliable model that demonstrates a respectful space for conversation. When parents promote a high conversation orientation, children may feel less caught between their parents. This orientation between children and parents creates an association between conditions 
that mitigate experiences of relational turbulence following divorce. Families who partake in high conversation feel comfortable sharing thoughts, beliefs, and feelings overall promoting openness (Leustek \& Theiss, 2017, p. 173). Parents must be mindful of the approaches they take when communicating about the divorce or their ex-spouse as the information they share as it may be perceived wrongly by their young adult child (Leustek \& Theiss, 2017, p. 184). For adult children of divorce, they must be actively aware of their involvement in these conversations and the information they desire to acquire and the potential implications these findings may have on their overall well-being (Leustek \& Theiss, 2017, p. 184). Feeling as though they can engage in information-seeking behaviours may be viewed as a form of social support from the family that helps to facilitate coping and reducing uncertainty when addressing divorce (Mikucki-Enyart et al., 2018, p. 477).

\section{Conclusion}

Although marital disruption is not uniformly harmful to children and most adolescents and young adults with divorced parents develop into well-adjusted adults, the levels in which a marriage dissolution occurs can have a substantial impact on the perception of intimate relationships for these children of divorce. The findings within these studies prove the substantial effect parental divorce has on adult children and the formation of intimate relationships. There is an overlap in relational uncertainty and topic avoidance as it is a direct portrayal of communication outcomes in which individuals wish to avoid. This topic avoidance developed from relational uncertainty directly affects how an individual communicates throughout the relationship. This further encompasses doubts stemming from self-uncertainty, partner uncertainty, and relationship uncertainty. The way in which an individual appraises the threat of themselves and the relationship determines the information and conversations they wish to seek and avoid. The impact divorce has on adult children of divorces perception on close relationships acts as a foundation for reactivity creating relational turbulence when the development of the relationship intensifies. The communicatory patterns learnt by ACOD corresponds directly to the child's overall well-being and attitudes towards future relationships. The family-of-origin provides an individual with their first understanding of how people should treat one another and what is normal within intimate relationships. If a person only experienced a hostile environment throughout their parents' dissolution of marriage, they model their intimate relationships around the ideology that relationships are not permanent. There are consistent associations between one's familial experiences and their later attitudes on future and marital relationships. The quality of the parents' marriage can be directly associated with future relationship experiences for the children of divorce. It is important that children of divorce think about what they want out of love and romantic relationships, learning what they can from their parents' separation. Children can be affected by their parents' divorce in different capacities depending on the nature of the divorce and as well as the parents' relationship post-divorce. 


\section{References}

Afifi, T. D., \& Schrodt, P. (2003). "Feeling Caught" as a Mediator of Adolescents' and Young Adults' Avoidance and Satisfaction with their Parents in Divorced and Non-Divorced Households. National Communication Association, 70(2), 142-173. doi:10.1080/0363775032000133791

Amato, P. R., \& Cheadle, J. (2005). The Long Reach of Divorce: Divorce and Child Well-Being Across Three Generations. Journal of Marriage and Family, 67, 191-206.

Amato, P. R., \& DeBoer, D. D. (2001). The Transmission of Marital Instability Across Generations: Relationship Skills or Commitment to Marriage? Journal of Marriage and Faily, 1038-1051.

Cui, M., \& Fincham, F. D. (2010). The Differential Effects of Parental Divorce and Marital Conflict on Young Adult Romantic Relationships. Personal Relationships, 17, 331-343. doi:10.1111/j.1475-6811.2010.01279.x

Knobloch, L. K., \& Carpenter-Theune, K. E. (2004). Topic Avoidance in Developing Romantic Relationships: Associations with Intimacy and Relational Uncertainty. Communication Research, 31(2), 173-205. doi:10.1177/0093650203261516

Leustek, J., \& Theiss, J. A. (2017). Family communication patterns that predict perceptions of upheaval and psychological well-being for emerging adult children following late-life divorce. Journal of Family Studies, 26(2), 169-187. doi:10.1080/13229400.2017.1352531

Mikucki-Enyart, S. L., Petitte, S. R., \& Wilder, S. E. (2018). Relational Uncertainty Management in Adult Children of Divorce. Journal of Applied Communication Research, 46(4), 469-490. doi:https://doi.org/10.1080/00909882.2018.1500025

Soloman, D. H., \& Knobloch, L. K. (2004). A Model of Relational Turbulence: The Role of Intimacy, Relational Uncertainty, and Interference from Partners in Appraisals of Irritations. Journal of Social and Personal Relationships, 21(6), 795-816. doi: $10.1177 / 0265407504047838$

Weigel, D. J. (2007). Parental Divorce and the Types of Commitment-Related Messages People Gain from Their Families of Origin. Journal of Divorce \& Remarriage, 47, 15-32. doi:10.1300/J087v47n01_02 